\title{
Protective effects of dietary arginine supplementation against oxidative stress in weaned piglets
}

\author{
Ping Zheng ${ }^{1,2}$, Bing $\mathrm{Yu}^{1,2}$, Jun $\mathrm{He}^{1,2}$, Gang Tian ${ }^{1,2}$, Yuheng Luo ${ }^{1}$, Xiangbing Mao ${ }^{1,2}$, Keying Zhang ${ }^{1}$, \\ Lianqiang Che ${ }^{1,2}$ and Daiwen Chen ${ }^{1,2 *}$ \\ ${ }^{1}$ Animal Nutrition Institute, Sichuan Agricultural University, Xinkang Road 46\#, Ya'an, Sichuan Province 625014, \\ People's Republic of China \\ ${ }^{2}$ Animal Disease-Resistance Nutrition Key Laboratory of Sichuan Province, Ya'an 625014, People's Republic of China
}

(Submitted 14 March 2012 - Final revision received 3 August 2012 - Accepted 8 August 2012 - First published online 26 November 2012)

\section{Abstract}

Oxidative stress is detrimental to animals. Previous studies have indicated that arginine (Arg) may function as a potential substance against oxidative stress. The present study was conducted to explore the potential mechanisms behind the Arg-induced protective effects against oxidative stress in piglets. A total of thirty-six piglets were randomly allocated to six groups with six replicates per group. Piglets were subjected to three dietary treatments (namely two groups per treatment) in week 1 and fed with a basal diet (ArgL) or the basal diet supplemented with $0.8 \%(\mathrm{ArgM})$ or $1.6 \%(\mathrm{ArgH}) \mathrm{L}$-Arg, respectively. On day 8 , piglets were injected intraperitoneally either with diquat $(10 \mathrm{mg} / \mathrm{kg}$ body weight) or sterile saline. The whole trial lasted $11 \mathrm{~d}$. Results showed that dietary Arg supplementation did not affect growth performance in week 1 . Oxidative stress significantly decreased the growth performance of piglets $(P<0.05)$. However, $\operatorname{ArgH}$ attenuated the negative effects of oxidative stress on feed intake and significantly increased the total antioxidant capacity in the liver under oxidative stress $(P<0.05)$. Both ArgM and $\mathrm{ArgH}$ enhanced the activities of plasma glutathione peroxidases and superoxide dismutases and decreased the IL- 6 and TNF- $\alpha$ mRNA level in the liver under oxidative stress $(P<0 \cdot 05)$. The present study not only shows that Arg can function as a potential nutrient to alleviate oxidative stress responses through the enhancement of antioxidant capacity, and inhibition of the expression of inflammatory cytokines, but the results also suggest that alleviation of oxidative stress responses using dietary nutrient components deserves further attention in the future.

\section{Key words: Arginine: Antioxidant capacity: Oxidative stress: Diquat: Weaned piglets}

Oxidative stress is an imbalance between the generation of reactive oxygen species (ROS) and the antioxidant defence capacity of the body. Reactive oxygen species, such as superoxide and $\mathrm{H}_{2} \mathrm{O}_{2}{ }^{(1)}$, are constantly generated from oxygen in all aerobic metabolism and pathogenic processes. Under normal circumstances, the ROS in the body are maintained at certain steady-state levels and excessive oxidative radicals are generally eliminated by the antioxidant system including non-enzymic components (for example, glutathione, Se, vitamin $\mathrm{E}$ and vitamin $\mathrm{C}$ ) and a series of antioxidant enzymes (for example, superoxide dismutase (SOD) and glutathione peroxidase (GPx)). For weaned piglets, numerous factors such as environmental factors, weaning and infection can lead to oxidative stress, which may result in growth retardation, disease and even death to piglets.

L-Arginine (Arg), a basic amino acid, serves as an essential precursor for the synthesis of biologically important molecules such as protein, ornithine, proline, polyamines, creatine, NO and agmatine ${ }^{(2)}$. Traditionally, it has been thought of as a non-essential amino acid. However, it is a nutritionally essential amino acid for young mammals and adults under stress and illness ${ }^{(3)}$. Arg deficiency causes growth retardation, intestinal and reproductive dysfunction, impaired immune and neurological development, cardiovascular and pulmonary abnormalities, impaired wound healing, hyperammonaemia, and even death in animals ${ }^{(4)}$. Our previous study found that oxidative stress depressed the growth performance and decreased the concentration of plasma Arg in weaned piglets ${ }^{(5)}$, indicating that Arg may serve as a limited amino acid under oxidative stress. As previous studies ${ }^{(6,7)}$ have indicated that Arg may function as a potential substance against oxidative stress, in the present study, we hypothesised that dietary Arg supplementation could attenuate oxidative stress in piglets. Although many studies have been previously

Abbreviations: ADFI, average daily feed intake; ADG, average daily gain; Arg, arginine; ArgH, basal diet and supplementation with 1.6\% synthetic L-arginine; ArgL, basal diet; ArgM, basal diet and supplementation with $0 \cdot 8 \%$ synthetic L-arginine; F:G, feed intake:gain ratio; GPx, glutathione peroxidase; MDA, malondialdehyde; SOD, superoxide dismutase; TAC, total antioxidant capacity.

*Corresponding author: Professor Daiwen Chen, fax +86 835 2882088, email dwchen@sicau.edu.cn 
conducted to evaluate the effect of Arg supplementation on oxidative stress in animal models and patients ${ }^{(8,9)}$, no studies explored the changes of the antioxidant defence system in weaned piglets after dietary Arg supplementation under oxidative stress. Pro-oxidants such as diquat are widely used to induce oxidative stress in different animal models ${ }^{(5,10-13)}$. The aim of the present study was to evaluate if dietary Arg supplementation could enhance body antioxidative capacity and attenuate diquat-induced oxidative stress in weaned piglets, and offer a theoretical basis for developing Arg as a dietary stress-resistant component in feeds.

\section{Materials and methods}

\section{Animals}

The experimental procedures followed the actual law of animal protection that was approved by the Animal Care Advisory Committee of Sichuan Agricultural University. All crossbred (Pig Improvement Company; PIC) male piglets weaned at 21 (SEM 1) $\mathrm{d}$ and housed individually in a stainless-steel cage $(1.5 \mathrm{~m} \times 0.7 \mathrm{~m} \times 1.0 \mathrm{~m})$ in a temperature- and humidity-controlled room, maintained at $24-26^{\circ} \mathrm{C}$ on a $12 \mathrm{~h}$ light-dark cycle starting at 08.00 hours. All piglets were given free access to distilled water and feed. Before the formal experiment, all piglets were fed with a basal diet for the start of the experiment of $7 \mathrm{~d}$.

\section{Experimental procedure}

A total of thirty-six piglets (8.67 (SEM 0.43) kg, 28 (SEM 1) d) were allocated to six groups with six replicates per group. Piglets were subjected to three dietary treatments (namely two groups per treatment) in week 1 and fed a basal diet supplemented with varying concentrations of Arg. Diets were as follows: ArgL (basal diet), ArgM (basal diet and supplementation with $0 \cdot 8 \%$ synthetic L-Arg) and ArgH (basal diet and supplementation with $1.6 \%$ synthetic L-Arg). These diets were formulated according to National Research Council $1998^{(14)}$ requirements and PIC requirements of practical commercial feed for all nutrients. Ingredients and nutrient composition of the experimental diets are shown in Table 1. All feed was mash. Feed intake was recorded, and feed refusal was collected and weighed daily. Piglets were weighed before the morning meal on days 1,8 and 12. Average daily feed intake (ADFI), average daily gain (ADG) and the ratio of feed intake:gain (F:G) were calculated. The whole trial lasted for $11 \mathrm{~d}$.

At 08.00 hours on day 8 , piglets in each dietary treatment were intraperitoneally injected with diquat at $10 \mathrm{mg} / \mathrm{kg}$ body weight or sterile $0.9 \% \mathrm{NaCl}$ solution of the same amount, respectively. Diquat (diquat dibromide monohydrate, PS365; Sigma Co.) was dissolved in isotonic saline and filter-sterilised. The concentration of diquat solution was $10 \mathrm{mg} / \mathrm{ml}$.

Before injection $(0 \mathrm{~h})$ and at $6,24,48$ and $96 \mathrm{~h}$ postinjection, blood ( $10 \mathrm{ml}$ per pig) was collected from the portal vein precava into heparinised polyethylene tubes (Axygen Biotechnology Co. Ltd). Plasma was prepared by
Table 1. Dietary composition and nutrient levels

\begin{tabular}{|c|c|c|c|}
\hline & ArgL & ArgM & $\mathrm{ArgH}$ \\
\hline \multicolumn{4}{|l|}{ Ingredients (\%) } \\
\hline Maize & $25 \cdot 23$ & 24.43 & 23.63 \\
\hline Extruded maize & $25 \cdot 00$ & $25 \cdot 00$ & $25 \cdot 00$ \\
\hline Soyabean meal, dehulled (46\% CP) & $5 \cdot 60$ & $5 \cdot 60$ & $5 \cdot 60$ \\
\hline Fish meal & $5 \cdot 00$ & $5 \cdot 00$ & $5 \cdot 00$ \\
\hline Pig plasma protein powder & 3.00 & 3.00 & 3.00 \\
\hline Whey powder (3\% CP) & $10 \cdot 00$ & $10 \cdot 00$ & $10 \cdot 00$ \\
\hline Puffed soyabean & 11.00 & 11.00 & 11.00 \\
\hline Maize protein powder (55\% CP) & 5.00 & $5 \cdot 00$ & $5 \cdot 00$ \\
\hline Wheat bran & $2 \cdot 00$ & 2.00 & $2 \cdot 00$ \\
\hline Cane sugar & 3.00 & 3.00 & 3.00 \\
\hline Fat powder* & 1.00 & 1.00 & 1.00 \\
\hline L-Lysine $\mathrm{HCl}$ & 0.60 & 0.60 & 0.60 \\
\hline DL-Methionine & 0.18 & $0 \cdot 18$ & 0.18 \\
\hline L-Tryptophan & 0.06 & 0.06 & 0.06 \\
\hline L-Threonine & 0.20 & 0.20 & 0.20 \\
\hline Choline chloride & $0 \cdot 10$ & $0 \cdot 10$ & 0.10 \\
\hline Calcium carbonate & 0.90 & 0.90 & 0.90 \\
\hline Calcium phosphate & 0.80 & $0 \cdot 80$ & 0.80 \\
\hline $\mathrm{NaCl}$ & $0 \cdot 13$ & $0 \cdot 13$ & $0 \cdot 13$ \\
\hline Pig compound enzyme $\dagger$ & $0 \cdot 10$ & $0 \cdot 10$ & 0.10 \\
\hline Acidifying agent $\ddagger$ & $0 \cdot 10$ & $0 \cdot 10$ & 0.10 \\
\hline Vitamin and mineral premix§ & 1.00 & 1.00 & 1.00 \\
\hline L-Arginine & 0.00 & $0 \cdot 80$ & 1.60 \\
\hline Total & $100 \cdot 00$ & $100 \cdot 00$ & $100 \cdot 00$ \\
\hline \multicolumn{4}{|l|}{ Nutrient composition } \\
\hline Digestible energy (calculated, MJ/kg) & $14 \cdot 35$ & 14.35 & 14.35 \\
\hline $\mathrm{CP}$ (analysed) & $19 \cdot 50$ & 19.55 & $19 \cdot 70$ \\
\hline $\mathrm{Ca}$ (calculated) & 0.79 & 0.79 & 0.79 \\
\hline P, available (calculated) & 0.43 & 0.43 & 0.43 \\
\hline L-Lysine (analysed) & 1.45 & 1.37 & 1.49 \\
\hline Methionine + cysteine (analysed) & 0.66 & 0.69 & 0.67 \\
\hline L-Tryptophan (calculated) & 0.28 & 0.28 & 0.28 \\
\hline L-Threonine (analysed) & 0.92 & 0.90 & 0.89 \\
\hline L-Arginine (analysed) & 0.95 & 1.62 & $2 \cdot 48$ \\
\hline
\end{tabular}

ArgL, basal diet; ArgM, basal diet and supplementation with $0.8 \%$ synthetic L-arginine; $\mathrm{ArgH}$, basal diet and supplementation with $1.6 \%$ synthetic L-arginine; $\mathrm{CP}$, crude protein.

${ }^{*}$ A pig fat powder (Beijing AnHaiWei Farm Co. Ltd).

†A pig compound enzyme (Wuhan Sunhy Animal Pharmacy Co. Ltd). $\ddagger$ An organic compound acidifier ACID LAC ${ }^{\mathrm{TM}}$ Dry (Kemin Industries, Inc.).

$\S$ The vitamin and mineral premix (maize powder as diluent) provided the following amounts per kg complete diet: retinol, $8.4 \mathrm{mg}$; cholecalciferol, $0.008 \mathrm{mg}$; vitamin $\mathrm{E}$, $20 \mathrm{mg}$; menadione, $1 \mathrm{mg}$; vitamin $\mathrm{B}_{12}, 0.03 \mathrm{mg}$; riboflavin, $5 \mathrm{mg}$; niacin, $20 \mathrm{mg}$; pantothenic acid, $15 \mathrm{mg}$; folic acid, $0.5 \mathrm{mg}$; thiamin, $1.5 \mathrm{mg}$; pyridoxine, $2 \mathrm{mg}$; biotin, $0.1 \mathrm{mg} ; \mathrm{Fe}, 100 \mathrm{mg}\left(\mathrm{FeSO}_{4} \cdot 7 \mathrm{H}_{2} \mathrm{O}\right) ; \mathrm{Cu}, 6 \mathrm{mg}\left(\mathrm{CuSO}_{4} \cdot 5 \mathrm{H}_{2} \mathrm{O}\right) ; \mathrm{Zn}, 100 \mathrm{mg}$ $\left(\mathrm{ZnSO}_{4} \cdot 7 \mathrm{H}_{2} \mathrm{O}\right) ; \mathrm{Mn}, 4 \mathrm{mg}\left(\mathrm{MnSO}_{4} \cdot \mathrm{H}_{2} \mathrm{O}\right) ; \mathrm{Se}, 0.3 \mathrm{mg}\left(\mathrm{Na}_{2} \mathrm{SeO}_{3} \cdot 5 \mathrm{H}_{2} \mathrm{O}\right) ; \mathrm{I}, 0.14 \mathrm{mg}(\mathrm{KI})$.

centrifuging the blood $\left(3000 \mathrm{~g}, 4^{\circ} \mathrm{C}, 5 \mathrm{~min}\right)$ and immediately stored at $-20^{\circ} \mathrm{C}$.

After the blood was collected at $96 \mathrm{~h}$ post-injection, piglets were slaughtered by exsanguination according to protocols approved by the Sichuan Agricultural University Animal Care Advisory Committee. Liver samples were removed and snapfrozen in liquid $\mathrm{N}_{2}$ and then stored at $-80^{\circ} \mathrm{C}$ for assay.

\section{Analytical methods}

Measurement of cortisol in plasma. Plasma cortisol concentration was analysed by a commercially available ELISA kit (R\&D System). The methods were according to the manufacturer's instructions.

Measurement of enzyme activity. GPx, SOD, total antioxidant capacity (TAC) and concentration of malondialdehyde (MDA) in plasma and liver were measured by assay kits 
from Nanjing Jiancheng Bioengineering Institute. The methods were according to the manufacturer's instructions.

RNA isolation and reverse transcription. Total RNA was extracted from samples of liver using TRIzol reagent (TaKaRa) according to the manufacturer's instructions. The concentration of RNA in the final preparations was calculated from the optical density at $260 \mathrm{~nm}$. The integrity of RNA was verified by denaturing agarose gel electrophoresis. Reverse transcription was performed using the Prime Script ${ }^{\mathrm{TM}}$ RT reagent kit (TaKaRa) with a $2 \mu \mathrm{g}$ RNA sample according to the manufacturer's instructions. The cDNA was used as the template for PCR.

Real-time quantitative PCR. Real-time quantitative PCR was performed in an Option Monitor 3 Real-Time PCR Detection System (Bio-Rad) using the SYBR Green Supermix (TaKaRa). Expression levels of TNF- $\alpha$ and IL- 6 in liver were analysed by real-time quantitative PCR with SYBR Green PCR reagents (TaKaRa) and performed by means of the Option DNA Engine (Bio-Rad) using the following cycle parameters: $95^{\circ} \mathrm{C}$ for $10 \mathrm{~s}$, and forty cycles at $95^{\circ} \mathrm{C}$ for $5 \mathrm{~s}$ and $61^{\circ} \mathrm{C}$ for $20 \mathrm{~s}$ with a final extension at $72^{\circ} \mathrm{C}$ for $5 \mathrm{~min}$. The gene-specific primers used are listed in Table 2. All primers were purchased from TaKaRa. Fluorescence detection was carried out immediately at the end of each annealing step, and the purity of the amplification was confirmed by analysing the melting curves. Relative gene expression to the housekeeping gene $\beta$-actin was performed in order to correct for the variance in amounts of RNA input in the reactions.

Each primer pair used yielded a single peak in the melting curve and a single band with the expected size in agarose gel. The relative gene expressions compared with the housekeeping gene $\beta$-actin were calculated using the $\mathrm{Pfaffl}^{(15)}$ method.

\section{Statistical analysis}

Data before the injection were analysed by one-way ANOVA. Data after the injection were analysed by two-way ANOVA using the general linear model procedure. Model main effects included Arg levels (ArgL, ArgM and ArgH) and oxidative stress (injection of diquat or saline). Probability values of $<0.05$ were considered to indicate a significant difference and values between 0.05 and 0.10 to indicate a trend. Variable means for treatments showing significant differences in the ANOVA were separated by Duncan's multiple-range test $(P<0.05)$. Values were expressed as means with their standard errors. All statistical analysis was performed using SPSS 17.0 (SPSS, Inc.).

\section{Results}

\section{Growth performance}

The effects of dietary Arg levels and oxidative stress on growth performance of piglets are summarised in Table 3. From day 1 to day 7 (pre-injection), supplementation with Arg did not affect $(P>0 \cdot 10)$ ADG, ADFI and F:G. From day 8 to day 11 (post-injection), oxidative stress induced by diquat significantly decreased ADG and ADFI $(P<0 \cdot 05)$. Supplementation of Arg tended to increase the ADFI of piglets under oxidative stress $(P=0.053)$. Moreover, ArgH significantly increased ADFI relative to ArgL under oxidative stress $(P<0 \cdot 05)$. All piglets subjected to oxidative stress induced by diquat lost weight, so we did not calculate F:G for these groups. Arg $\times$ oxidative stress interaction effects did not affect piglet ADG and ADFI.

\section{Cortisol concentration}

As shown in Table 4, supplementation with Arg did not affect the concentration of cortisol before diquat injection. Oxidative stress induced by diquat significantly increased the concentration of cortisol at 48 and $96 \mathrm{~h}$ in the ArgL group after injection. ArgM and ArgH significantly decreased the concentration of cortisol at $48 \mathrm{~h}$ compared with ArgL under oxidative stress. ArgM significantly decreased the concentration of cortisol at 96 h compared with ArgL under oxidative stress.

\section{Malondialdehyde production and enzyme activities in plasma}

Table 5 shows the effect of Arg and diquat on the activity of antioxidant enzymes and MDA in plasma. Supplementation with Arg did not affect the activity of GPx before diquat injection. Oxidative stress induced by diquat significantly decreased the activity of GPx at 6, 24 and $48 \mathrm{~h}$ after injection. ArgM or/and ArgH significantly increased the activity of GPx at 6, 48 and $96 \mathrm{~h}$ compared with ArgL under oxidative stress. It also can be seen from Table 5 that the activity of GPx in the plasma of piglets had the trend of first decreasing then gradually rising and the activity of GPx was the lowest at $24 \mathrm{~h}$ under oxidative stress. Arg $\times$ oxidative stress interaction effects had a significant effect on GPx at 6 and $96 \mathrm{~h}$ after injection.

As shown in Table 5, supplementation of Arg significantly decreased the SOD activity of piglets compared with ArgL before injection. Oxidative stress induced by diquat significantly decreased the activity of SOD at 24 and $48 \mathrm{~h}$ after injection. ArgH significantly decreased the activity of SOD at 24 and $96 \mathrm{~h}$ after injection with sterile saline. ArgM or/and $\operatorname{ArgH}$

Table 2. Primers used for the real-time analyses

\begin{tabular}{llcc}
\hline Primer & Sequence $5^{\prime}$ to $3^{\prime}$ & Product size (bp) & Accession number \\
\hline $\begin{array}{l}\text { B-Actin forward } \\
\beta-A c t i n \text { reverse }\end{array}$ & $\begin{array}{l}\text { ccacgaaactaccttcaactcc } \\
\text { gtgatctccttctgcatcctgt }\end{array}$ & 132 & DQ845171 \\
$\begin{array}{l}\text { TNF- } \alpha \text { forward } \\
\text { TNF- } \alpha \text { reverse }\end{array}$ & $\begin{array}{l}\text { gctcttctgcctactgcacttc } \\
\text { ggcttatctgaggtttgagacg }\end{array}$ & 123 & X57321 \\
$\begin{array}{l}\text { IL-6 forward } \\
\text { IL-6 reverse }\end{array}$ & $\begin{array}{l}\text { ggagacctgcttgatgagaatc } \\
\text { gtactaatctgcacagcctcgac }\end{array}$ & 117 & M80258 \\
\hline
\end{tabular}


Table 3. Effects of dietary arginine (Arg) supplementation and diquat injection on growth performance of weaned piglets (Mean values with their standard errors)

\begin{tabular}{|c|c|c|c|c|c|c|c|c|c|c|}
\hline \multirow[b]{2}{*}{ Response } & \multicolumn{3}{|c|}{ SS } & \multicolumn{3}{|c|}{ os } & \multirow[b]{2}{*}{ SEM } & \multicolumn{3}{|c|}{$P$} \\
\hline & ArgL & ArgM & $\mathrm{ArgH}$ & ArgL & ArgM & $\mathrm{ArgH}$ & & Arg & OS & $\operatorname{Arg} \times \mathrm{OS}^{*}$ \\
\hline \multicolumn{11}{|c|}{$1-7 \mathrm{~d}(n 12)$} \\
\hline ADG (g) & 285 & 280 & 263 & - & - & - & 5 & - & - & - \\
\hline ADFI (g) & 331 & 322 & 313 & - & - & - & 6 & - & - & - \\
\hline$F: G$ & $1 \cdot 17$ & $1 \cdot 15$ & $1 \cdot 19$ & - & - & - & 0.01 & - & - & - \\
\hline \multicolumn{11}{|l|}{$8-11 d(n 6)$} \\
\hline$A D G(g)$ & 354 & 340 & 348 & 54 & 68 & 60 & 26 & 1.000 & 0.000 & 0.865 \\
\hline ADFI $(g)$ & 436 & 403 & 443 & 148 & 158 & 242 & 24 & 0.053 & 0.000 & 0.260 \\
\hline$F: G$ & 1.23 & $1 \cdot 19$ & 1.31 & n/a & n/a† & n/a† & 0.04 & - & - & - \\
\hline
\end{tabular}

SS, injection with sterile saline; OS, oxidative stress (injection with diquat); $\operatorname{ArgL}, 0.95 \% \operatorname{Arg} ; \operatorname{ArgM}, 1.62 \% \operatorname{Arg} ; \operatorname{ArgH}, 2.48 \% \operatorname{Arg}$; $A D G$, average daily gain; ADFI, average daily feed intake; F:G, feed:gain ratio; n/a, not applicable.

${ }^{*}$ Arg $\times$ oxidative stress interaction effect.

†Some pigs' weight gain was negative after injection, so not calculated.

significantly increased the activity of SOD at 6,48 and $96 \mathrm{~h}$ compared with ArgL under oxidative stress. It also can be seen from Table 5 that the activity of SOD in plasma of piglets had the trend of first decreasing then gradually rising and the activity of SOD was the lowest at $24 \mathrm{~h}$ under oxidative stress. Arg $\times$ oxidative stress interaction effects had a significant effect on SOD at 48 and $96 \mathrm{~h}$ after injection.

Activity of TAC in plasma was detected (Table 5). Supplementation with Arg did not affect the activity of TAC before diquat injection. Oxidative stress induced by diquat significantly decreased the activity of TAC at $6 \mathrm{~h}$ after injection. ArgM or/and ArgH significantly increased the activity of TAC at 6, 24 and $48 \mathrm{~h}$ compared with ArgL under oxidative stress. Arg $\times$ oxidative stress interaction effects had a significant effect on TAC at 6, 24 and $48 \mathrm{~h}$ after injection.

Supplementation with Arg did not affect MDA before diquat injection (Table 5). Oxidative stress induced by diquat significantly increased MDA at 6, 24, 48 and $96 \mathrm{~h}$ after injection. ArgM or/and ArgH significantly decreased MDA at 6, 48 and $96 \mathrm{~h}$ compared with ArgL under oxidative stress. It also can be seen from Table 5 that the concentration of MDA in the plasma of piglets had the trend of first increasing then gradually decreasing and the concentration of MDA was the highest at $24 \mathrm{~h}$ under oxidative stress. Arg $\times$ oxidative stress interaction effects had a significant effect on MDA at $6 \mathrm{~h}$ after injection.

\section{Malondialdehyde production and enzyme activities in liver}

The data for MDA production and enzyme activities in liver are presented in Table 6 . Oxidative stress induced by diquat did not affect the activity of GPx in liver $(P>0.05)$. Dietary Arg supplementation significantly increased the activities of GPx in liver under non-oxidative stress and oxidative stress $(P<0.05)$. Oxidative stress induced by diquat significantly decreased the activity of SOD and TAC in the ArgL group in liver $(P<0.05)$. ArgM or/and ArgH significantly increased the activities of SOD and TAC in liver under oxidative stress compared with ArgL $(P<0.05)$. Supplementation of Arg could decrease the concentration of MDA under nonoxidative stress.

\section{Gene expression}

As shown in Fig. 1, ArgM and ArgH significantly decreased IL-6 mRNA level in liver compared with ArgL under nonoxidative stress and oxidative stress. Oxidative stress induced by diquat had no effect on TNF- $\alpha$ mRNA level in liver of the ArgL group ( $P>0.05)$. Supplementation with Arg significantly decreased the TNF- $\alpha$ mRNA level in liver under oxidative stress $(P<0 \cdot 05)$.

Table 4. Effects of dietary arginine supplementation and diquat injection on cortisol concentration in plasma of weaned piglets $(\mathrm{ng} / \mathrm{ml})$ (Mean values with their standard errors)

\begin{tabular}{|c|c|c|c|c|c|c|c|c|c|c|}
\hline \multirow[b]{2}{*}{ Response } & \multicolumn{3}{|c|}{ SS } & \multicolumn{3}{|c|}{ os } & \multirow[b]{2}{*}{ SEM } & \multicolumn{3}{|c|}{$P$} \\
\hline & ArgL & ArgM & $\overline{\mathrm{ArgH}}$ & ArgL & ArgM & ArgH & & $\operatorname{Arg}$ & os & $\operatorname{Arg} \times O^{*}$ \\
\hline $\mathrm{Oh}(n 12)$ & $88 \cdot 11$ & 83.06 & $85 \cdot 07$ & - & - & - & 4.04 & - & - & - \\
\hline $24 \mathrm{~h}(n 6)$ & $66.99^{b}$ & $62.98^{\mathrm{b}}$ & $94.04^{a}$ & $65.52^{\mathrm{b}}$ & $91 \cdot 17^{a}$ & $79 \cdot 95^{a, b}$ & 3.97 & 0.061 & 0.542 & 0.048 \\
\hline $48 \mathrm{~h}(n 6)$ & $90 \cdot 05^{a}$ & $77.53^{\mathrm{a}}$ & $63.54^{a}$ & $199 \cdot 21^{b}$ & $57.59^{a}$ & $58 \cdot 04^{a}$ & $12 \cdot 86$ & 0.004 & 0.192 & 0.034 \\
\hline $96 \mathrm{~h}(n 6)$ & 93.64 & $141 \cdot 74$ & 63.35 & $212 \cdot 88$ & 128.97 & $158 \cdot 16$ & $13 \cdot 17$ & 0.317 & 0.006 & 0.054 \\
\hline
\end{tabular}

SS, injection with sterile saline; OS, oxidative stress (injection with diquat); ArgL, 0.95\% Arg; ArgM, 1.62\% Arg; ArgH, $2.48 \%$ Arg.

a,b,c Mean values within a row with unlike superscript letters were significantly different $(P<0.05)$.

${ }^{*}$ Arg $\times$ oxidative stress interaction effect. 
Table 5. Effects of dietary arginine supplementation and diquat injection on the activities of antioxidant enzymes and malondialdehyde (MDA) in plasma of weaned piglets

(Mean values with their standard errors)

\begin{tabular}{|c|c|c|c|c|c|c|c|c|c|c|}
\hline \multirow[b]{2}{*}{ Response } & \multicolumn{3}{|c|}{ SS } & \multicolumn{3}{|c|}{ os } & \multirow[b]{2}{*}{ SEM } & \multicolumn{3}{|c|}{$P$} \\
\hline & ArgL & ArgM & $\mathrm{ArgH}$ & ArgL & ArgM & $\mathrm{ArgH}$ & & Arg & OS & $\operatorname{Arg} \times \mathrm{OS}^{*}$ \\
\hline \multicolumn{11}{|l|}{$\mathrm{GPx}(\mathrm{U} / \mathrm{ml})$} \\
\hline $\mathrm{Oh}(n 12)$ & $662 \cdot 4$ & 653.3 & 658.8 & - & - & - & $5 \cdot 82$ & - & - & - \\
\hline $6 \mathrm{~h}(n 6)$ & $643.5^{c}$ & $647 \cdot 6^{\mathrm{c}}$ & $635.2^{\mathrm{c}}$ & $546 \cdot 6^{\mathrm{a}}$ & $593 \cdot 8^{\mathrm{b}}$ & $618 \cdot 6^{\mathrm{b}, \mathrm{c}}$ & 7.85 & 0.005 & 0.000 & 0.001 \\
\hline $24 \mathrm{~h}(n 6)$ & 606.7 & $631 \cdot 1$ & 629.5 & 504.0 & $515 \cdot 6$ & 523.3 & $11 \cdot 11$ & 0.013 & 0.000 & 0.655 \\
\hline $48 \mathrm{~h}(n 6)$ & $616 \cdot 6$ & $614 \cdot 8$ & $616 \cdot 6$ & 523.9 & $546 \cdot 9$ & $567 \cdot 7$ & 7.98 & 0.057 & 0.000 & 0.057 \\
\hline $96 \mathrm{~h}(n 6)$ & $624 \cdot 6^{\mathrm{a}, \mathrm{b}, \mathrm{c}}$ & $602 \cdot 0^{a, b}$ & $593.4^{a}$ & $637 \cdot 4^{\mathrm{b}, \mathrm{c}}$ & $661 \cdot 5^{\mathrm{c}, \mathrm{d}}$ & $686 \cdot 6^{d}$ & 7.96 & 0.631 & 0.000 & 0.002 \\
\hline \multicolumn{11}{|l|}{$\operatorname{SOD}(\mathrm{U} / \mathrm{ml})$} \\
\hline $\mathrm{Oh}(n 12)$ & $65 \cdot 75^{\mathrm{c}}$ & $61 \cdot 13^{\mathrm{a}}$ & $63 \cdot 18^{b}$ & - & - & - & 0.49 & - & - & - \\
\hline $6 \mathrm{~h}(n 6)$ & $59 \cdot 08$ & $60 \cdot 34$ & $62 \cdot 30$ & $59 \cdot 15$ & $61 \cdot 78$ & $62 \cdot 30$ & 0.51 & 0.009 & 0.532 & 0.709 \\
\hline $24 \mathrm{~h}(n 6)$ & $64 \cdot 28$ & $63 \cdot 70$ & 62.44 & $58 \cdot 38$ & 57.75 & $58 \cdot 24$ & 0.55 & 0.161 & 0.000 & 0.163 \\
\hline $48 \mathrm{~h}(n 6)$ & $67.90^{\mathrm{C}}$ & $66 \cdot 50^{b, c}$ & $67 \cdot 73^{c}$ & $63 \cdot 18^{\mathrm{a}}$ & $64.05^{\mathrm{a}, \mathrm{b}}$ & $65.98^{b}$ & 0.40 & 0.000 & 0.000 & 0.001 \\
\hline $96 \mathrm{~h}(n 6)$ & $70.56^{c}$ & $69 \cdot 30^{b, c}$ & $68 \cdot 32^{a, b}$ & $66 \cdot 85^{\mathrm{a}}$ & $69 \cdot 30^{\mathrm{b}, \mathrm{c}}$ & $70 \cdot 53^{c}$ & 0.32 & 0.219 & 0.163 & 0.000 \\
\hline \multicolumn{11}{|l|}{ TAC (U/ml) } \\
\hline $\mathrm{Oh}(n 12)$ & 1.38 & 1.34 & 1.40 & - & - & - & 0.04 & - & - & - \\
\hline $6 \mathrm{~h}(n 6)$ & $1 \cdot 38^{b}$ & $1 \cdot 39^{b}$ & $1 \cdot 39^{b}$ & $1.05^{a}$ & $1.02^{a}$ & $1 \cdot 32^{b}$ & 0.05 & 0.022 & 0.000 & 0.025 \\
\hline $24 \mathrm{~h}(n 6)$ & 1.42 & 1.27 & $1 \cdot 33$ & 1.23 & $1 \cdot 36$ & 1.56 & 0.05 & 0.162 & 0.458 & 0.023 \\
\hline $48 \mathrm{~h}(n 6)$ & $1.06^{\mathrm{a}}$ & $1.03^{\mathrm{a}}$ & $1 \cdot 23^{\mathrm{a}, \mathrm{b}}$ & $1 \cdot 11^{\mathrm{a}}$ & $1.39^{b}$ & $1 \cdot 23^{a, b}$ & 0.04 & 0.016 & 0.003 & 0.003 \\
\hline $96 \mathrm{~h}(n 6)$ & 0.76 & 0.99 & 0.91 & 1.36 & 1.30 & 1.40 & 0.07 & 0.661 & 0.000 & 0.446 \\
\hline \multicolumn{11}{|c|}{ MDA (nmol/ml) } \\
\hline $\mathrm{Oh}(n 12)$ & 1.67 & 1.63 & 1.66 & - & - & - & 0.02 & - & - & - \\
\hline $6 \mathrm{~h}(n 6)$ & $1 \cdot 35^{\mathrm{a}}$ & $1.41^{a, b}$ & $1.37^{a, b}$ & $1.85^{c}$ & $1 \cdot 61^{b, c}$ & $1.67^{c}$ & 0.05 & 0.135 & 0.000 & 0.017 \\
\hline $24 \mathrm{~h}(n 6)$ & 2.03 & 2.03 & 2.00 & $3 \cdot 10$ & 3.55 & 3.23 & 0.15 & 0.296 & 0.000 & 0.325 \\
\hline $48 \mathrm{~h}(n 6)$ & 1.68 & 1.65 & 1.61 & 2.06 & 1.85 & 2.02 & 0.05 & 0.210 & 0.000 & 0.237 \\
\hline $96 \mathrm{~h}(n 6)$ & 1.69 & 1.67 & 1.37 & 1.84 & $1 \cdot 81$ & 1.45 & 0.05 & 0.000 & 0.031 & 0.853 \\
\hline
\end{tabular}

SS, injection with sterile saline; OS, oxidative stress (injection with diquat); ArgL, 0.95\% Arg; ArgM, 1.62\% Arg; ArgH, $2.48 \%$ Arg; GPx, glutathione peroxidase; SOD, superoxide dismutase; TAC, total antioxidant capacity.

a,b,c Mean values within a row with unlike superscript letters were significantly different $(P<0.05)$.

${ }^{*}$ Arg $\times$ oxidative stress interaction effect.

\section{Discussion}

In livestock production, numerous factors can induce oxidative stress to damage cellular antioxidant defence. Oxidative stress can result in suboptimal health conditions of livestock and a reduction in production efficiency. L-Arg is the key physiological substrate of NO, polyamines, creatine, agmatine, glutamate and proline with enormous biological importance $^{(16,17)}$. Kim \& $\mathrm{Wu}^{(18)}$ showed that supplementation of 0.2 and $0.4 \%$ Arg to suckling pigs enhanced ADG by 28 and $66 \%$ between ages 7 and $21 \mathrm{~d}$, respectively. In the present study, dietary Arg supplementation did not affect $(P>0 \cdot 10)$ ADG, ADFI and F:G before diquat injection. In fact, the effect of Arg supplementation on the performance of piglets is related to the age of piglets, the dose of Arg and the period of supplementation. For example, Hernandez et al. ${ }^{(19)}$ reported that supplementing $0.6 \%$ Arg to a diet containing $1 \cdot 1 \%$ Arg had no influence on the performance of piglets in the first week after weaning, but significantly increased feed intake and ADG in the third week after weaning.

Oxidative stress significantly decreased ADG and ADFI $(P<0.05)$, and increased F:G $(P<0.05)$. This is consistent with previous results that oxidative stress significantly reduced the growth performance of piglets ${ }^{(20)}$. Arg deficiency may occur under various nutritional and clinical conditions. Accumulating evidence has indicated that Arg levels in

Table 6. Effects of dietary arginine supplementation and diquat injection on the activities of antioxidant enzymes and malondialdehyde (MDA) in liver of weaned piglets

(Mean values with their standard errors)

\begin{tabular}{|c|c|c|c|c|c|c|c|c|c|c|}
\hline \multirow[b]{2}{*}{ Response } & \multicolumn{3}{|c|}{ SS } & \multicolumn{3}{|c|}{ os } & \multirow[b]{2}{*}{ SEM } & \multicolumn{3}{|c|}{$P$} \\
\hline & $\operatorname{ArgL}$ & ArgM & $\mathrm{ArgH}$ & ArgL & ArgM & $\mathrm{ArgH}$ & & Arg & os & $\operatorname{Arg} \times \mathrm{OS}^{*}$ \\
\hline GPx (U/mg protein) $(n 6)$ & $75 \cdot 0^{\mathrm{a}}$ & $94 \cdot 9^{\mathrm{c}}$ & $92 \cdot 9^{b, c}$ & $79 \cdot 3^{\mathrm{a}}$ & $86.0^{\mathrm{b}}$ & $90 \cdot 0^{\mathrm{b}, \mathrm{c}}$ & $2 \cdot 30$ & 0.000 & 0.191 & 0.026 \\
\hline SOD (U/mg protein) $(n 6)$ & $361 \cdot 8^{\mathrm{b}, \mathrm{c}}$ & $379.7^{\mathrm{c}}$ & $345 \cdot 4^{\mathrm{a}, \mathrm{b}}$ & $330 \cdot 4^{\mathrm{a}}$ & $344 \cdot 5^{a, b}$ & $377 \cdot 8^{\mathrm{c}}$ & 6.94 & 0.045 & 0.053 & 0.000 \\
\hline TAC (U/mg protein) $(n 6)$ & $1 \cdot 11^{\mathrm{b}, \mathrm{c}}$ & $1 \cdot 13^{\mathrm{b}, \mathrm{c}}$ & $1 \cdot 17^{\mathrm{c}, \mathrm{d}}$ & $0.91^{\mathrm{a}}$ & $1.05^{\mathrm{b}}$ & $1 \cdot 20^{\mathrm{d}}$ & 0.03 & 0.000 & 0.001 & 0.001 \\
\hline MDA (nmol/mg protein) $(n 6)$ & $6 \cdot 7^{b}$ & $5 \cdot 6^{\mathrm{a}, \mathrm{b}}$ & $4 \cdot 9^{\mathrm{a}}$ & $5 \cdot 4^{\mathrm{a}, \mathrm{b}}$ & $4 \cdot 9^{\mathrm{a}}$ & $5 \cdot 6^{a, b}$ & 0.43 & 0.133 & 0.223 & 0.068 \\
\hline
\end{tabular}

SS, injection with sterile saline; OS, oxidative stress (injection with diquat); ArgL, 0.95\% Arg; ArgM, 1.62\% Arg; ArgH, $2.48 \%$ Arg; GPx, glutathione peroxidase; SOD, superoxide dismutase; TAC, total antioxidant capacity.

${ }^{a, b, c}$ Mean values within a row with unlike superscript letters were significantly different $(P<0.05)$.

${ }^{*}$ Arg $\times$ oxidative stress interaction effect. 
(A)

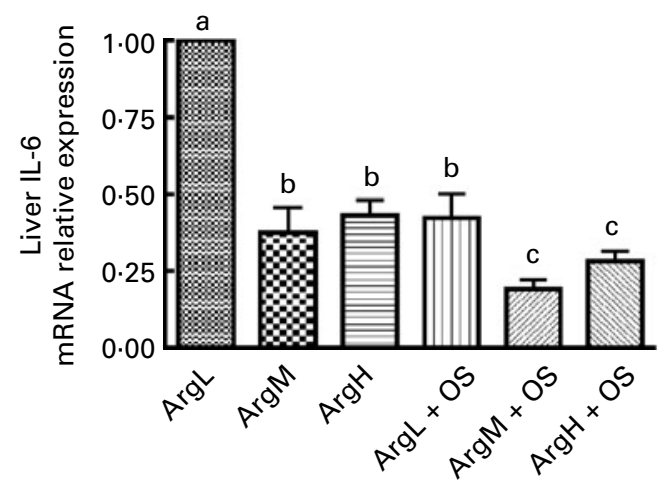

(B)

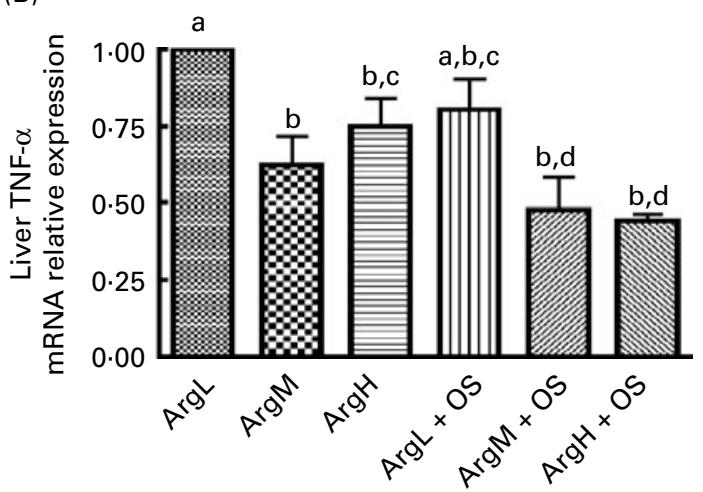

Fig. 1. Effects of dietary arginine (Arg) supplementation and diquat injection on (A) IL-6 and (B) TNF- $\alpha$ mRNA relative expression in liver of weaned piglets. Values are means $(n 6)$, with their standard errors represented by vertical bars. ${ }^{a, b, c, d}$ Mean values with unlike letters were significantly different $(P<0.05)$. ArgL, $0.95 \%$ Arg; ArgM, $1.62 \%$ Arg; ArgH, $2.48 \%$ Arg; OS, oxidative stress (injection with diquat).

plasma are markedly reduced in the sepsis pig model ${ }^{(21)}$. In the present study, supplementation of Arg tended to increase the ADFI of piglets under oxidative stress $(P=0.053)$, and this is more profound at the high inclusion level of $\operatorname{Arg}(\operatorname{ArgH})$. Feed intake of pigs often decreases under stress or injury conditions, and increasing feed intake of pigs under stress conditions helps relieve stress and repair. Our experiment showed that high-Arg supplementation (ArgH) was helpful to piglets under oxidative stress through increasing feed intake. Again, the beneficial effects of dietary Arg supplementation under stress conditions could be widely variable depending on many factors, such as the age of piglets and the level of Arg in the diet. Liu et $a l^{(22)}$ reported that dietary supplementation of 0.5 or $1.0 \%$ Arg significantly alleviated weight loss compared with lipopolysaccharidechallenged pigs.

Cortisol, a corticosteroid hormone, is an important physiological effector of homeostasis and commonly used as a biomarker of stress ${ }^{(23)}$. In the present study, oxidative stress significantly increased the concentration of cortisol, and the concentration of MDA in plasma was also increased after diquat injection. MDA which remains after termination of lipid peroxidation provides the basis for the thiobarbituric acid test for measuring lipid peroxidation and products in body fluid ${ }^{(24)}$. Lipid peroxidation is a biochemical oxidative degradation of unsaturated fatty acids that causes irreversible denaturation of essential proteins. GPx and SOD are two major antioxidant enzymes in mammals, which reduce the accumulation of $\mathrm{H}_{2} \mathrm{O}_{2}$ and organic hydroperoxides in the body. The activity of the two enzymes is commonly used to monitor the body's antioxidative capability ${ }^{(25-27)}$. In the present study, the activities of the two enzymes in plasma were significantly decreased after diquat injection, suggesting that the antioxidative capabilities of piglets were damaged under oxidative stress. These results are consistent with the findings of Yuan et $a l .{ }^{(20)}$ and Zheng et al. ${ }^{(5)}$. Moreover, we found that dietary supplementation of Arg significantly decreased the concentration of cortisol and MDA, increased the activities of GPX and SOD, and increased the contents of TAC in plasma under oxidative stress. These results indicate that supplementation of Arg can effectively relieve the oxidative stress of piglets. These results are consistent with the findings in the sickle-shaped erythrocyte anaemia model of mice in which supplementation of Arg increased the content of antioxidants in plasma ${ }^{(9)}$. Furthermore, we also studied the antioxidant capability of the liver. The results in liver were same as plasma, that supplementation of Arg could significantly increase the activities of GPx, SOD and TAC.

Inflammation is the consequence of oxidative stress, and the pathways that generate the mediators of inflammation, such as adhesion molecules and interleukins, are all induced by oxidative stress. IL-6, a central regulator of inflammatory diseases, is produced at the site of inflammation and plays a key role in the acute-phase response ${ }^{(28)}$. In the present study, IL-6 mRNA expression in the liver significantly decreased in the $\operatorname{ArgL}$ group at $96 \mathrm{~h}$ after diquat injection compared with the isotonic saline-injected group. The results from the present study are, however, not consistent with previous findings that oxidative stress increased the concentration of IL-6 in plasma ${ }^{(29)}$. This is probably due to the fact that diquat is removed quickly ${ }^{(30,31)}$. Previous research indicated that when male rats were administered $45 \mathrm{mg} / \mathrm{kg}$ diquat dibromide, $95 \%$ of the compound was recovered in urine and faeces in $96 \mathrm{~h}^{(32)}$. In the present study, the time we detected the IL- 6 mRNA expression change was after $96 \mathrm{~h}$ of diquat injection. IL- 6 is induced often together with the pro-inflammatory cytokines TNF- $\alpha$ in many alarm conditions ${ }^{(33,34)}$. Overproduction of pro-inflammatory cytokines has a negative influence on animal health ${ }^{(35)}$. In the present study, diquat-induced oxidative stress did not influence TNF- $\alpha$ mRNA expression in liver, and supplementation of Arg could significantly suppress TNF- $\alpha$ mRNA in liver. TNF- $\alpha$ is a cytokine involved in systemic inflammation and can induce inflammation. It is possible that supplementing Arg to pigs attenuates oxidative injury through suppressing the expression of TNF- $\alpha$. Moreover, IL-6 also plays a crucial role in the regulation of local and systemic acute inflammatory responses by down-regulating the expression of pro-inflammatory cytokines ${ }^{(36-38)}$. For instance, IL- 6 was shown to inhibit the production of TNF- $\alpha$, and stimulated the release of soluble TNF- $\alpha$ receptors ${ }^{(39)}$. Therefore, the protective effects of Arg on oxidative injury may be attributed in part to the elevated expression of hepatic IL-6, 
which subsequently decreases the production of the proinflammatory cytokine TNF- $\alpha$.

In conclusion, dietary Arg supplementation significantly alleviates a reduction in feed intake and other negative stress responses in weaned piglets under oxidative stress. The beneficial effects of dietary Arg supplementation are due in part to the enhancement of the total antioxidative capacity, and inhibition of the expression of inflammatory cytokines. Moreover, the present results also suggest that alleviation of the oxidative stress responses using dietary nutrient components, such as Arg, deserves further attention in the future.

\section{Acknowledgements}

The authors express their gratitude to the Program for Changjiang Scholars and Innovative Research Team in the University of Ministry of Education of China (no. IRTO555-5) and the earmarked fund for China Agriculture Research System (no. CARS-36) for financial support. P. Z. carried out the study. B. Y. designed the study. J. H. and G. T. assisted in manuscript preparation. L. C., Y. L. and X. M. assisted with all the data analyses. K. Z. and D. C. contributed to the experimental design. There is no conflict of interest to disclose

\section{References}

1. Nappi AJ \& Vass E (1998) Hydroxyl radical formation via iron-mediated Fenton chemistry is inhibited by methylated catechols. Biochim Biophys Acta 1380, 55-63.

2. Wu G \& Morris SM Jr (1998) Arginine metabolism: nitric oxide and beyond. J Biochem 336, 1-17.

3. Wu G, Davis PK, Flynn NE, et al. (1997) Endogenous synthesis of arginine plays an important role in maintaining arginine homeostasis in postweaning growing pigs. $J$ Nutr 127, 2342-2349.

4. Wu G, Knabe DA \& Kim SW (2004) Arginine nutrition in neonatal pigs. $J$ Nutr 134, 2783S-2790S.

5. Zheng P, Yu B, Lv M, et al. (2010) Effects of oxidative stress induced by diquat on arginine metabolism of postweaning pigs. Asian-Aust J Anim Sci 23, 98-106.

6. Suschek CV, Schnorr O, Hemmrich K, et al. (2003) Critical role of l-arginine in endothelial cell survival during oxidative stress. Circulation 107, 2607-2614.

7. Lin CC, Tsai WC, Chen JY, et al. (2008) Supplements of 1-arginine attenuate the effects of high-fat meal on endothelial function and oxidative stress. Int J Cardiol 127, $337-341$.

8. El-Mesallamy HO, Abdel Hamid SG \& Gad MZ (2008) Oxidative stress and asymmetric dimethylarginine are associated with cardiovascular complications in hemodialysis patients: improvements by l-arginine intake. Kidney Blood Press Res 31, 189-195.

9. Dasgupta T, Hebbel RP \& Kaul DK (2006) Protective effect of arginine on oxidative stress in transgenic sickle mouse models. Free Radic Biol Med 41, 1771-1780.

10. Fussell KC, Udasin RG, Gray JP, et al. (2011) Redox cycling and increased oxygen utilization contribute to diquatinduced oxidative stress and cytotoxicity in Chinese hamster ovary cells overexpressing NADPH-cytochrome P450 reductase. Free Radic Biol Med 50, 874-882.
11. Lu T, Piao XL, Zhang Q, et al. (2010) Protective effects of Forsythia suspensa extract against oxidative stress induced by diquat in rats. Food Chem Toxicol 48, 764-770.

12. Osburn WO, Wakabayashi N, Misra V, et al. (2006) Nrf2 regulates an adaptive response protecting against oxidative damage following diquat-mediated formation of superoxide anion. Arch Biochem Biophys 454, 7-15.

13. Yumino K, Kawakami I, Tamura M, et al. (2002) Paraquatand diquat-induced oxygen radical generation and lipid peroxidation in rat brain microsomes. J Biochem 131, 565-570.

14. National Research Council (1998) Nutrient Requirements of Swine, 10th ed. Washington, DC: National Academy Press.

15. Pfaffl MW (2001) A new mathematical model for relative quantification in real-time RT-PCR. Nucleic Acids Res 29, e45.

16. Montanez R, Rodriguez-Caso C, Sanchez-Jimenez F, et al. (2008) In silico analysis of arginine catabolism as a source of nitric oxide or polyamines in endothelial cells. Amino Acids 34, 223-229.

17. Wu G, Bazer FW, Davis TA, et al. (2007) Important roles for the arginine family of amino acids in swine nutrition and production. Livest Sci 112, 8-22.

18. Kim SW \& Wu G (2004) Dietary arginine supplementation enhances the growth of milk-fed young pigs. J Nutr $\mathbf{1 3 4}$ $625-630$

19. Hernandez A, Hansen CF, Mullan BP, et al. (2009) L-Arginine supplementation of milk liquid or dry diets fed to pigs after weaning has a positive effect on production in the first three weeks after weaning at 21 days of age. Anim Feed Sci Technol 154, 102-111.

20. Yuan SB, Chen DW, Zhang KY, et al. (2007) Effects of oxidative stress on growth performance, nutrient digestibilities and activities of antioxidative enzymes of weanling pigs. Asian-Aust J Anim Sci 20, 1600-1605.

21. Luiking YC, Poeze M, Ramsay G, et al. (2005) The role of arginine in infection and sepsis. J Parenter Enteral Nutr 29, S70-S74.

22. Liu Y, Huang J, Hou Y, et al. (2008) Dietary arginine supplementation alleviates intestinal mucosal disruption induced by Escherichia coli lipopolysaccharide in weaned pigs. Br J Nutr 100, 552-560.

23. Kusters B, Peppelman M, Timmers H, et al. (2012) Response to: Morphological distinction of cortisol-producing and aldosterone-producing adrenal cortical adenomas: not only possible but a critical clinical responsibility. Histopathology 60, 1016-1017.

24. Placer Z, Cushman L \& Johnson B (1966) Estimation of product of lipid peroxidation (malonyldialdehyde) in biochemical systems. Anal Biochem 16, 359-364.

25. Chirino YI \& Pedraza-Chaverri J (2009) Role of oxidative and nitrosative stress in cisplatin-induced nephrotoxicity. Exp Toxicol Pathol 61, 223-242.

26. Andreazza AC, Kauer-Sant'Anna M, Frey BN, et al. (2008) Oxidative stress markers in bipolar disorder: a meta-analysis. J Affect Disord 111, 135-144.

27. Coyle CH, Martinez LJ, Coleman MC, et al. (2006) Mechanisms of $\mathrm{H}_{2} \mathrm{O}_{2}$-induced oxidative stress in endothelial cells. Free Radic Biol Med 40, 2206-2213.

28. Dominic SCR (2009) Role of interleukin-6 in the anemia of chronic disease. Semin Arthritis Rheum 38, 382-388.

29. Furukawa S, Fujita T, Shimabukuro M, et al. (2004) Increased oxidative stress in obesity and its impact on metabolic syndrome. J Clin Invest 114, 1752-1761.

30. Kurisaki E \& Sato H (1979) Tissue distribution of paraquat and diquat after oral administration in rats. Forensic Sci Int 14, 165-170. 
31. Daniel JW \& Gage JC (1966) Absorption and excretion of diquat and paraquat in rats. Br J Ind Med 23, 133-136.

32. Office of Environmental Health Hazard Assessment California Environmental Protection Agency, Fan AM, Alexeeff GV (2000) Public health goals for DIQUAT in drinking water. http://www.oehha.ca.gov/water/phg/pdf/ diquat.pdf (accessed August 2012).

33. Silverman MN, Miller AH, Biron CA, et al. (2004) Characterization of an interleukin-6- and adrenocorticotropindependent, immune-to-adrenal pathway during viral infection. Endocrinology 145, 3580-3589.

34. Zarkovie M, Ignjatovie S, Dajak M, et al. (2008) Cortisol response to ACTH stimulation correlates with blood interleukin 6 concentration in healthy humans. Eur J Endocrinol 159, 649-652.
35. Mckay D \& Baird A (1999) Cytokine regulation of epithelial permeability and ion transport. Gut 44, 283-289.

36. Gabay C (2006) IL-6 and chronic in?ammation. Arthritis Res Ther $\mathbf{8}$, Suppl. 2, S3.

37. Xing Z, Gauldie J, Cox G, et al. (1998) IL-6 is an antiinflammatory cytokine required for controlling local or systemic acute inflammatory responses. J Clin Invest 101, 311-320.

38. Maggio M, Guralnik JM, Longo DL, et al. (2006) Interleukin-6 in aging and chronic disease: a magnificent pathway. $J$ Gerontol A Biol Sci Med Sci 61, 575-584.

39. Schindler R, Mancilla J, Endres S, et al. (1990) Correlations and interactions in the production of interleukin-6 (IL-6), IL-1, and tumor necrosis factor (TNF) in human blood mononuclear cells: IL-6 suppresses IL-1 and TNF. Blood 75, 40-47. 